\title{
Learners' Perceptions toward the Web-based Distance Learning Activities/Assignments Portion of an Undergraduate Hybrid Instructional Model
}

\author{
Alex Koohang \\ University of Wisconsin - Milwaukee, \\ WI, USA
}

\author{
Angela Durante \\ Lewis University, IL, USA
}

durantan@lewisu.edu

\section{koohang@uwm.edu}

\section{Executive Summary}

The purpose of this study is to measure learners' perceptions toward the Web-based distance learning activities/assignments portion of a hybrid program. These activities and assignments were designed based on a set of appropriate instructional parameters and objectives. By measuring learners' perceptions, this study attempts to find whether these activities/assignments promote learning. This study gives attention to the variables of age, gender, and experience with the Internet to find whether these variables are significant factors in learners' perceptions toward the Web-based distance learning activities/assignments portion of the hybrid program. A ten-item Likert-type instrument was designed based on the instructional parameters and objectives. The instrument collects information about the learners' perceptions of Web-based distance learning activities and assignments portion of the hybrid program. The subjects of this study were 106 students who were enrolled in an undergraduate hybrid program in management designed for working adults. In addition to descriptive analyses, three separate Analyses of Variance (one-way ANOVA) were conducted to answer the research questions in this study. Results indicated that overall students gravely perceived that the Web-based distance learning activities/assignments portion of their hybrid program promoted learning. Age and gender were not significant factors. However, there was a significant difference among levels of learners' experience with the Internet and their perceptions toward the Web-based distance learning activities/assignments portion of the hybrid program. Subjects who had more experience with the Internet indicated significantly higher perceptions toward the Web-based distance learning activities/assignments portion of the hybrid program. The findings are discussed and recommendations are made based on the results of this study.

Keywords: Web-based Distance Learning, Instructional Design, Perceptions, Courseware, Adult Learning, Hybrid Instructional Model

\section{Introduction}

Distance learning generally is identified as all types of formal instruction that are conducted when teachers and learners are not located in the same

Material published as part of this journal, either on-line or in print, is copyrighted by the publisher of the Journal of Information Technology Education. Permission to make digital or paper copy of part or all of these works for personal or classroom use is granted without fee provided that the copies are not made or distributed for profit or commercial advantage AND that copies 1) bear this notice in full and 2) give the full citation on the first page. It is permissible to abstract these works so long as credit is given. To copy in all other cases or to republish or to post on a server or to redistribute to lists requires specific permission and payment of a fee. Contact Editor@JITE.org to request redistribution permission. place (Gilbert, 1995). In the mid-1990s, the Internet was hailed as the promising tool for connecting the remote teacher and learner. Indeed the Internet is flourishing in that promise. McNealy (1999) predicted that by 2002 about 84 percent of four-year colleges would be offering on-line courses via the Internet and the American Distance Education Consortium (2002, online) confirms that all forms of technology "are increasingly common components of the instructional 
experience for American college students." From its incarnations, Web-based distance learning's merits have been touted for their asynchronous benefits. The promise of anywhere, anyplace, anytime education (Rosenkrans, 2001; Downes, 1998; Cooper, 1999; Gubbins, Clay, \& Perkins, 1999; Rose, 1999; Seymour, Durante, \& Koohang, 1998) has intrigued both instructor and student alike.

An increasing number of universities are experimenting with the hybrid instructional model - the newest entrant into the familiar classroom experience (Young, 2002). The hybrid instructional model is a blend of conventional face-to-face instruction and Web-based distance learning. In other words, a hybrid instructional model consists of both classroom face-to-face meetings and distance learning. The hybrid instructional model brings together classroom and technology as essential partners in instructional design. Courses designed in the hybrid instructional model move a significant portion of the learning activities from the classroom to the Web and reduce the amount of seat time. The instructor and the student have the advantages of real-time exchange in scheduled classes but have the benefit of continuing the discussion and assignments in the spaces between meetings (Young, 2002; Garnham \& Kaleta, 2002).

Adult students were among the first to embrace the asynchronous model for its convenience. Adult students are characteristically independent learners who are self-directed in establishing their learning objectives. They are more likely than other students to be involved in distance education programs (Thompson, 1988).

Similarly, adults are particularly suited for the hybrid instructional model because it also relies on students' self-motivation. Adult learners tend to self-select, knowing that their success requires selfdiscipline and good time management (Koohang \& Durante, 1998).

The present study took place in a university that has maintained its home campuses in a large U.S. Midwestern urban region - a highly competitive college market for more than 100 years. In the last five years, the university has sought to incorporate Web-based distance learning into its conventional face-toface programs using the hybrid instructional model. The first program to be dedicated to the hybrid approach was an accelerated undergraduate degree completion program in management designed for working adult learners. In each course, the students are required to meet face-to-face once a week. They are also required to log into a courseware known as WebCT and complete weekly Web-based distance learning activities/assignments portion of the course. These activities/assignments are designed specifically for the Web-based distance learning activities/assignments portion of the course.

The hybrid program began in the 2001 - 2002 academic year. Courses in the program are upper division level and covered the subject areas of organizational behavior, communications, research design, human resources, management, marketing, finance, business ethics, and strategic management.

To ensure the quality of the instruction, the Web-based distance learning activities/assignments portion of the hybrid program was designed based on a set of instructional parameters and objectives using appropriate androgogy (pedagogy for adult learners) to meet the specific learning needs of adult learners. Research acknowledges that the course assignments and delivery methods of distance learning courses must include appropriate elements of instructional design (Randall, 2001). They must also be designed to specifically meet the needs of learners (Randall, 2001; Egbert \& Thomas, 2001).

The instructional parameters and objectives for Web-based distance learning instruction used in this study represent five areas drawn from or synthesized from theory and practice in the fields of adult learning and distance education (Brookfield, 1991; Clark, 1999; Knowles, Holton, \& Swanson, 1998). These areas were chosen in consultation with faculty experts and an external expert in curriculum design. The five areas are:

1. Incorporation of learning principles and strategies that include active learning, collaboration, and cooperation. 
2. Inclusion of real-world and real-work problems that complement the learning content -- adult learning employs learners' experiences so they go from what they know to what they don't know.

3. Encouragement of decision-making, problem solving, formulation of inferences and calculation of plausibility -- adults learn from applied experience as related to content and theory.

4. Inclusion of practice in evaluating viewpoints.

5. Inclusion of interactive activities to advance discussion and critical thinking -- adults learn from other adults in exchange via group process and teams.

The purpose of this study is to measure learners' perceptions toward the Web-based distance learning activities/assignments portion of the hybrid program that was designed based on the above instructional parameters and objectives. By measuring learners' perceptions, this study attempts to find whether these activities/assignments promote learning among learners. In view of that, this study gives attention to three selected variables: age, gender, and experience with the Internet. Older population makes a large portion of all Web-based distance learners (Thomson, 1998). Therefore, it is important to understand if differences in perceptions toward the Web-based distance learning activities/assignments portion of the hybrid program exist among various age groups within the adult population.

Gender differences have been reported in the literature as affecting perceptions in general (Hackett, Mirvis, \& Sales, 1991). Consequently, gender was included as a matter of understanding if differences of perceptions toward the Web-based distance learning activities/assignments portion of the hybrid program occurred between male and female respondents. Experience with the Internet was included because research has documented the relationship between experience and user acceptance of technology in general (Koohang, 1989). The more experience a user has with the technology the more he or she tends to accept it. The user acceptance may in turn promote learning. This may be true with adult learners' perceptions toward the Web-based distance learning activities/assignments portion of the hybrid program.

\section{Methodology}

\section{The Instrument}

A ten-item Likert-type instrument was designed to collect information about the learners' perceptions toward Web-based distance learning activities/assignments portion of the hybrid program to find whether these activities/assignments promote learning. The instrument presents positively worded statements. Each statement has five alternatives to choose from: strongly agree, agree, neither agree nor disagree, disagree, and strongly disagree. The responses to the items were recorded so that strongly agree $=5$, agree $=4$, neither agree nor disagree $=3$, disagree $=2$, and strongly disagree $=1$. A higher score indicates more favorable perceptions toward the Web-based distance learning activities/assignments portion of the hybrid program. (See Table 1)

The content validity of this instrument was established by a panel of experts consisting of five professors who were teaching in the undergraduate hybrid program in management. The items of this instrument were chosen from an original pool of 16 statements. They were based on the parameters and objectives used for designing the Web-based distance learning activities/assignments portion of the hybrid program. The panel of experts determined that these items measure learners' perceptions toward Web-based distance learning activities/assignments portion of the hybrid program to find whether these activities/assignments promote learning. 
Learners' Perceptions toward the Web-based Distance Learning Activities/Assignments Portion of the Hybrid Program

\section{SECTION 1}

Please answer the following questions by circling the appropriate number:
1) Your age:
2) Your Gender:
(1) 20 or younger
(1) Male
(1) $1-2$ Years
(2) $21-30$
(2) Female
(2) $3-5$ Years
(3) $31-40$
(3) Over 5 Years
(4) Over 40

3) Experience with the Internet:

\section{SECTION 2}

Using the scale below, please indicate your response to each of the items that follow by circling the number that best describes your feeling.

\section{SCALE:}

$5=$ Strongly Agree, 4 = Agree, $3=$ Neither Agree nor Disagree, $2=$ Disagree, $1=$ Strongly Disagree

\section{Web-based distance learning activities/assignments portion of the course:}

1. Contribute positively to my learning experience.

2. Make me understand the importance of learning from sharing real-world experiences.

3. Enhance my ability to understand and evaluate viewpoints.

$\begin{array}{lllll}5 & 4 & 3 & 2 & 1\end{array}$

4. Encourage my decision-making and problem solving skills.

5. Enhance my ability to think logically.

6. Encourage me to develop myself as a team member.

7. Sharpen my discussion/interaction skills.

8. Make me feel more involved with the class.

9. Give me the opportunity to relate my own experiences to the topics covered in the course.

10. Enhanced my ability to think critically.

Table 1. The Instrument

The internal consistency of this instrument was determined using 52 subjects who were studying in an undergraduate hybrid program in management. The sample used to determine internal consistency was independent of the sample of respondents used in the study itself. The calculated coefficient alpha reliability from the results for this instrument was .94 , which suggests that this instrument is suitable to measure learners' perceptions toward Web-based distance learning activities/assignments portion of the undergraduate hybrid program in management.

\section{Subjects and Procedure}

The instrument was administered on-site to 111 students who were enrolled in the accelerated undergraduate hybrid program in management designed for working adults. Five instruments were removed because of missing data yielding a final sample of 106. The subjects were male and females with various age groups who had completed at least 3 hybrid courses in the program. The subjects were given rationale for their participation in the study. They were assured that their responses would be anonymous and confidential.

\section{Research Questions}

This study seeks answers to the following questions:

1) Is there a significant difference among levels of subjects' age and their perceptions toward the Web-based distance learning activities/assignments portion of the hybrid program? 
2) Is there a significant difference between subjects' gender (male and female) and their perceptions toward the Web-based distance learning activities/assignments portion of the hybrid program?

3) Is there a significant difference among levels of subjects' experience with the Internet and their perceptions toward the Web-based distance learning activities/assignments portion of the hybrid program?

\section{Data Analysis}

In addition to conducting descriptive analyses, three separate Analyses of Variance (one-way ANOVA) were conducted to answer the research questions. ANOVA determines whether there is a significant difference between each selected variable and learners' perceptions toward the Web-based distance learning activities/assignments portion of the hybrid program. The predetermined level of significance of .05 was chosen for this study.

\section{Results}

\section{Demographics}

The subjects were 50 males (47.2 percent of total sample) and 56 females (52.8 percent of total sample). The subjects' ages varied in three different categories. The first category included 47 subjects (44.3 percent of total sample) who were between the ages of 21-30. The second category contained 37 subjects (34.9 percent of total sample) who were between the ages of 31-40. The third category had 22 subjects who were over 40 (20.8 percent of total sample). No subject was under the age of 21 . The subjects' experience with the Internet varied in three different categories. The first category contained 11 subjects (10.4 percent of total sample) with $1-2$ years of experience with the Internet. The second category had 27 subjects ( 25.5 percent of total sample) with $3-5$ years of experience with the Internet. The third category included 68 subjects (64.2 percent of total sample) with over 5 years of experience with the Internet.

\section{Descriptive Analysis}

Table 2 shows the descriptive analyses for the 10 items on the instrument. The total mean score for all the items was 4.16 . This indicates that overall students had high perceptions toward the activities/assignments that were designed for their Web-based distance learning portion of the hybrid program.

\begin{tabular}{|llllll}
\hline & & & & & \\
\hline & N & Min & Max & Mean & SD \\
\hline Item \#1 & 106 & 2 & 5 & 4.23 & .796 \\
Item \#2 & 106 & 2 & 5 & 4.17 & .810 \\
Item \#3 & 106 & 3 & 5 & 4.24 & .684 \\
Item \#4 & 106 & 2 & 5 & 4.28 & .658 \\
Item \#5 & 106 & 3 & 5 & 4.16 & .719 \\
Item \#6 & 106 & 2 & 5 & 4.09 & .775 \\
Item \#7 & 106 & 2 & 5 & 4.21 & .713 \\
Item \#8 & 106 & 2 & 5 & 4.11 & .797 \\
Item \#9 & 106 & 2 & 5 & 4.09 & .811 \\
Item \#10 & 106 & 2 & 5 & 4.08 & .813 \\
& & & & & \\
\hline
\end{tabular}

Table 2. Descriptive Analysis 


\section{ANOVA for Age}

The results of ANOVA for age indicated that there was no significant difference among levels of subjects' age and their perceptions toward the Web-based distance learning activities/assignments portion of the hybrid program $\left(\mathrm{F}_{2,103}=\right.$ $1.849, p=.163)$. Table 3 shows the results of ANOVA and mean scores for age.

\section{ANOVA for Gender}

The results of ANOVA for gender indicated that there was no significant difference between subjects' gender (male and female) and their perceptions toward the Web-based distance learning activities/assignments portion of the hybrid program $\left(\mathrm{F}_{1,104}=.009, p=.926\right)$. Table 4 shows the results of ANOVA and mean scores for gender.

\section{ANOVA for Years of Experience with the Internet}

The results of ANOVA for experience with the Internet indicated that there was a significant difference among levels of subjects' experience with the Internet and their perceptions toward the Webbased distance learning activities/assignments portion of the hybrid program $\left(F_{2,103}=3.332, p=.040\right)$. Subjects with more experience with the Internet scored higher. Table 5 shows the results of ANOVA and mean scores for years of experience with the Internet.

\begin{tabular}{|c|c|c|c|c|}
\hline & & SS & df & MS \\
\hline Between Groups & & 1.388 & 2 & .694 \\
\hline Within Groups & & 38.650 & 103 & .375 \\
\hline Total & & 40.038 & 105 & \\
\hline & Mean & & $\mathbf{N}$ & SD \\
\hline $21-30$ & 4.2766 & & 47 & .62003 \\
\hline $31-40$ & 4.1378 & & 37 & .57559 \\
\hline Over 40 & 3.9773 & & 22 & .65606 \\
\hline Total & 41660 & & 106 & \\
\hline
\end{tabular}

Table 3. ANOVA \& Mean Scores for Age

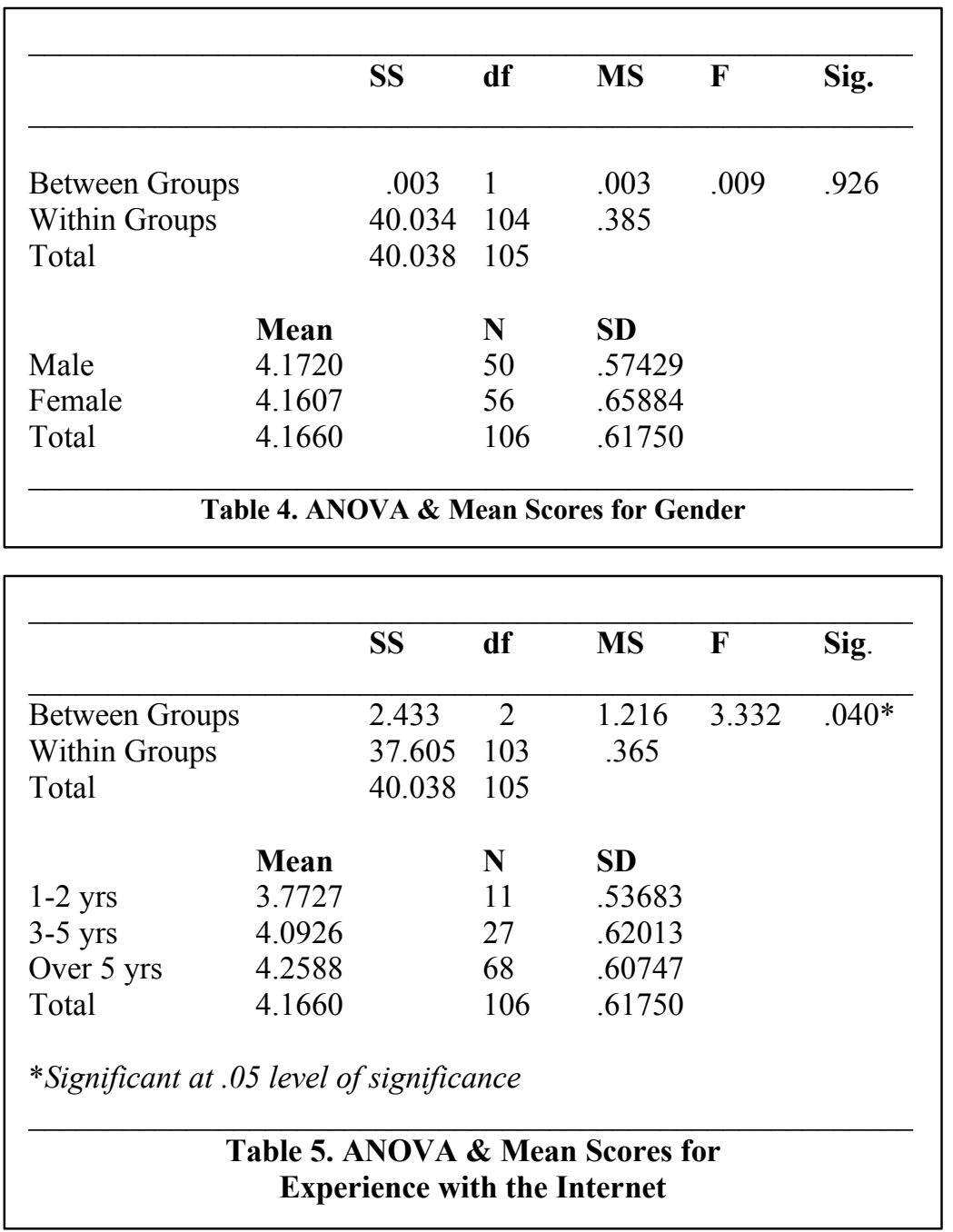

\section{Discussion}

Web-based distance learning continues to gain momentum in higher education and the hybrid instructional model that embraces Web-based distance learning is growing in use. Now that sophisticated technologies are possible to apply to the teaching-learning experience, the question of the quality of the learning experience, particularly for the learner, has become paramount. This study sought to measure learners' perceptions toward the Web-based distance learning activities/assignments portion of a hybrid 
program that was designed based on a set of instructional parameters and objectives. By measuring learners' perceptions, this study attempted to find whether these activities/assignments promote learning among learners.

The descriptive results of this study indicated that overall students positively perceived that the Webbased distance learning activities/assignments portion of their hybrid program promoted learning. These activities/assignments were designed to ensure the quality of Web-based instruction and meet the needs of the learners. They were based on a set of instructional parameters and objectives that included appropriate learning principles and theories geared toward adult learners. These instructional parameters and objectives included incorporation of learning principles and strategies that include active learning, collaboration, and cooperation; inclusion of real-world and real-work problems that complement the learning content; encouragement of decision-making, problem solving, formulation of inferences and calculation of plausibility; inclusion of practice in evaluating viewpoints; and inclusion of interaction activities to advance discussion and critical thinking.

This study gave attention to the variables of age, gender, and experience with the Internet in order to find whether these variables were significant factors in learners' perceptions toward the Web-based distance learning activities/assignments portion of the hybrid program. Age was found to be an insignificant factor. All age categories equally perceived that the Web-based distance learning activities/assignments portion of their hybrid program promoted learning. There was no significant difference for the variable of gender. Males and females equally perceived that the Web-based distance learning activities/assignments portion of their hybrid program promoted learning.

Experience with the Internet was found to be a significant factor. In other words, there was a significant difference among levels of learners' experience with the Internet and their perceptions toward the Webbased distance learning activities/assignments portion of their hybrid program. Subjects who had more experience with the Internet indicated significantly higher positive perceptions toward the Web-based distance learning activities/assignments portion of the hybrid program. Thus, subjects' increased experience with the Internet contributed to greater learning. This finding indicates that the success of Webbased instruction may depend upon increased experience with the Internet. Research has acknowledged that experience with technology in general affects user acceptance and thus increases one's comfort level in using the technology (Koohang, 1989). For this reason, a comfort level with technology may exist among the more experienced subjects in this study. Within the sample, 64.2 percent claim more than five years experience with the Internet. The second largest group in this sample, about 25.5 percent has a minimum of three years experience. Combined, the two largest groups in this study make up 89.7 percent. Their comfort with the media may influence their willingness to engage in Web-based distance learning activities/assignments that resulted in greater learning. This insight is worthy of further examination and is recommended for later study.

This study showed that the Web-based distance learning activities/assignments that were designed based on a set of appropriate instructional parameters and objectives promote learning among learners. Therefore, this study recommends that various and appropriate learning principles and theories that meet the specific needs of the learners should be included in the design of Web-based distance learning activities/assignment to promote learning. The activities/assignments that were designed based on a set of parameters and objectives in this study may be used to serve as a guide for the development of Web-based distance learning programs for adult learners.

In this study the underlying issues of the instructional design of Web-based distance learning activities/assignments relied primarily on the use of appropriate learning principles and conditions of learning. Nevertheless, there are various technologies such as hardware, software, and the Internet -- outside the scope of this study that may play important roles in facilitating Web-based distance learning. The uses of these technologies rely on interface design elements such as usability (satisfying the needs and speci- 
fications of learners), visualization (creating visually interesting and aesthetically pleasing pages), functionality (creating useful features to support a given task), and accessibility (designing for all users including those with certain disabilities). These elements are relevant to instructional design of Web-based distance learning and may play important roles in learning. Therefore, it may be worthwhile to include both appropriate learning principles/theories and user interface elements in design of Web-based distance learning activities/assignment. This notion deserves attention and should be included in future research.

\section{References}

American Distance Education Consortium. (2002). Use of Technology in College Instruction Expands. [Online] Retrieved December 20, 2002, from http://www.adec.edu/user/2001/campus_computing.html

Brookfield, S.D. (1991). Understanding and facilitating adult learning: A comprehensive analysis of principles and effective practices. San Francisco, Calif.: Jossey-Bass, Inc.

Clark III, J.F. (1999). The role of cooperative education in the adult learning environment. [Online] Retrieved from http://horizon.unc.edu/conferences/lc/papers/18.html

Cooper, L. (1999). Anatomy of an online course. THE Journal, 26(7).

Downes, S. (1998). The future of online learning. Online Journal of Distance Learning Administration, 1(3). [Online]. Retrieved December 20, 2002, from http://www.westga.edu/ distance/downes13.html

Egbert, J. \& Thomas, M. (2001). The new frontier: A case study in applying instructional design for distance teacher education. Journal of Technology and Teacher Education 9(3), p. 391-405.

Garnham, C. \& Kaleta, R (2002). Introduction to hybrid courses. Teaching with Technology Today. 8(6). [Online]. Retrieved from http://www.uwsa.edu/ttt/articles/garnham.htm

Gilbert, S. W. (1995). Why distance education? A special bulletin. American Association for Higher Education, 48.

Gubbins, J., Clay, M., \& Perkins, J. (1999, Spring). The development of an online course to teach public administrators computer utilization. Online Journal of Distance Learning, 2(1). [Online]. Retrieved December 20, 2002, from http://www.westga.edu/ distance/gubbins22.html

Hackett, E., Mirvis, P., \& Sales, A. (1991). Women's and men's expectation about the effect of new technology. Group and Organizational Studies, 16(1). 60-85.

Koohang, A. (1989). A study of attitudes toward computers: Anxiety, confidence, liking, and perception of usefulness. Journal of Research on Computing in Education, 22(2): 137-150.

Koohang, A. \& Durante A. (1998). Adapting the traditional face-to-face instructional approaches to on-line teaching and learning. Refereed Proceedings of International Association for Computer Information Systems.

Knowles, M., Holton, E., \& Swanson, R. (1998). The Adult Learner. $5^{\text {th }}$ edition. Texas: Gulf Publishing.

McNealy, S. (1999, September 16). How to turn the World Wide Web into a real-world education. USA Today, p. 17A.

Randall, B. (2001). Effective Web design and core communication issues: the missing components in Web-based distance education. Journal of Educational Multimedia and Hypermedia, 10(4), p. 357-67

Rose, R. (1999). Speaking up for online education. The concord consortium. [Online]. Retrieved December 20, 2002, from http://www.concord.org/newsletter/1999spring/speakingup.html

Rosenkrans, G. (2001). Design considerations for an effective online environment. Journalism \& Mass Communication Educator, 65(1) p. 43-61.

Seymour T., Durante A., \& Koohang A. (1998). Developing distance education programs/courses for Web-based delivery. $A$ Collection of Papers on Institutional Improvements. North Central Association for Colleges and Schools.

Thompson, G. (1988). Distance learners in higher education. In Chere Campbell Gibson (Ed.) Higher Education: Institutional Responses for Quality Outcomes. Madison, WI: Atwood Publishing, p 9-24.

Young, G. (2002, March 22). Hybrid teaching seeks to end the divide between traditional and online instruction. Chronicle of Higher Education. A33-A34 


\section{Biographies}

Dr. Alex Koohang is an associate professor and Director of undergraduate program in the School of Information Studies at University of Wisconsin - Milwaukee, USA. Dr. Koohang has designed, developed, and implemented various traditional, non-traditional, hybrid, and on-line courses/programs. His current research interests are in the areas of distance learning, usability, and information architecture. Dr. Koohang has written numerous scholarly manuscripts that are published in refereed journals and proceedings.

Dr. Angela Durante is Professor of Sociology and Dean of the College of Arts \& Sciences at Lewis University in Illinois, USA. Dr. Durante has been a pioneer in the development of on-line education, having initiated and administered some of the earliest asynchronous programming. Her research interests are in higher education processes and systems, in particular the issues and impact of technology for teaching and learning. 